\title{
Lung Hyperinflation Is Associated with Pulmonary Exacerbations in Adults with Cystic Fibrosis
}

\author{
Kosal Seng1, Lynn Fukushima², Pooja Patel², Arteen Pirverdian², Adupa Rao², \\ Joseph Milic-Emili ${ }^{3}$ Ahmet Baydur ${ }^{2 *}$ \\ ${ }^{1}$ Division of Geriatric, Hospital, Palliative and General Internal Medicine, Los Angeles, CA, USA \\ ${ }^{2}$ Division of Pulmonary and Critical Care Medicine, Keck School of Medicine, University of Southern California, \\ Los Angeles, CA, USA \\ ${ }^{3}$ Department of Physiology, McGill University (Emeritus), Montreal, Quebec, Canada \\ Email: "baydur@usc.edu
}

Received 6 February 2016; accepted 6 May 2016; published 9 May 2016

Copyright (C) 2016 by authors and Scientific Research Publishing Inc.

This work is licensed under the Creative Commons Attribution International License (CC BY).

http://creativecommons.org/licenses/by/4.0/

(c) (i) Open Access

\section{Abstract}

Background: Forced expiratory volume 1 second $\left(\mathrm{FEV}_{1}\right)$ has traditionally been used as a readily available marker of health in adult cystic fibrosis (CF). However, due to the obstructive nature of this disease, it is possible that lung hyperinflation could be more closely related to disease severity than is $\mathrm{FEV}_{1}$. The purpose of this study was to determine if hyperinflation is more closely associated with quality of life, functional status, and pulmonary exacerbations than FEV $_{1}$ in patients with CF. Methods: Sixty-eight adult patients with CF were evaluated in this retrospective study. We used IC and functional residual capacity (FRC) and their ratios to total lung capacity (TLC) as measures of lung hyperinflation. We used bivariate correlations and backwards regression analysis to assess possible associations between $\mathrm{FEV}_{1}$, lung hyperinflation, and measures of disease severity including questionnaire based quality of life, pulmonary exacerbation frequency, and mortality. The respiratory component of the Cystic Fibrosis Questionnaire-Revised (CRQ-R-Respiratory) was used as a measure of quality of life. Results: Both FEV $_{1}$ and IC were negatively correlated with pulmonary exacerbations over a 3 year period $\left(p=0.004, r^{2}=0.127 ; p<0.001, r^{2}=0.307\right.$, respectively), while FRC/TLC correlated positively with exacerbations $(p=0.007)$. Backwards regression analysis showed that among pulmonary function variables, IC had the strongest relationship with exacerbations over 3 years. A lower CFQ-R-Respiratory score was associated with greater mortality $(p=\mathbf{0 . 0 0 5})$. However, no statistically significant relationships were found between lung function and mortality. Conclusions: $\mathrm{FEV}_{1}$ and lung hyperinflation-as measured by IC and FRC/TLC-are both associated with pulmonary exacerbation frequency. This suggests that chronic dynamic hyperinflation contributes significantly to disease severity in adult cystic fibrosis.

\footnotetext{
${ }^{*}$ Corresponding author.
} 


\section{Keywords}

\section{Cystic Fibrosis, Hyperinflation, Inspiratory Capacity, Quality of Life}

\section{Introduction}

Cystic fibrosis (CF) is a progressive, multisystem disorder characterized by excessive production of thickened exocrine secretions. Bronchial secretions obstruct airflow and predispose individuals to recurrent respiratory infections, resulting in progressive airflow limitation, ventilation inhomogeneities [1]-[3], impaired gas exchange, and impaired respiratory muscle function [4]. Forced expiratory volume 1 second $\left(\mathrm{FEV}_{1}\right)$ percent predicted is often used as a marker of disease severity in CF. However, others have only been able to identify no [5] or weak although significant associations between $\mathrm{FEV}_{1}$ and quality of life (Spearman rho correlations 0.32 to 0.57) [6]. In addition, psychological and educational factors may be better predictors of work status than $\mathrm{FEV}_{1}$ in adults with cystic fibrosis [7].

Studies in COPD show that tidal expiratory flow limitation (tEFL) is more closely related to dyspnea than is $\mathrm{FEV}_{1}$ [8]. In COPD, tEFL has been associated with chronic dynamic hyperinflation during tidal breathing [9] defined as end-expiratory lung volume exceeding the relaxation volume of the respiratory system during quiet breathing. Tidal EFL leads to dynamic hyperinflation during exercise in patients with COPD as reflected by reduced inspiratory capacity (IC) and increased residual volume (RV), resulting in exercise intolerance [10]-[13]. Others have shown that the ratio of IC to total lung capacity (IC/TLC) is an independent predictor of mortality in patients with COPD [14]-[16]. In particular, in patients with the emphysematous phenotype of COPD an IC/ TLC ratio of $<25 \%$ is a significant predictor for mortality (hazard ratio 2.4, $p<0.0001$ ) [16]. Hyperinflation and its relation to morbidity and exercise intolerance have been assessed in children with CF [2], but not in adult CF patients.

The purpose of this study was to determine if hyperinflation is more closely associated with functional status and pulmonary exacerbations than is $\mathrm{FEV}_{1}$ in adult patients with $\mathrm{CF}$, using IC, functional residual capacity (FRC), residual volume (RV), and their ratios to TLC as indices of hyperinflation. In addition, we wanted to determine if baseline lung volume data including IC and IC/TLC best predicted pulmonary exacerbations and mortality over the 3 years following the first set of lung function measurements were obtained.

\section{Patients and Methods}

\subsection{Data Collection}

This retrospective data analysis was derived from clinical and lung function data obtained from adult CF patients evaluated in the CF Clinic at the Keck Medical Center, a 400-bed tertiary referral center of the University of Southern California, from 1999 to 2014. The data for the cohort were reviewed according to the following inclusion criteria: i) diagnosis of CF based on characteristic phenotypic features [17] [18]; ii) confirmed by pilocarpine iontophoresis sweat test measuring sodium and chloride values; iii) genotype identification using extended mutation screening of both alleles [19] [20]; and iv) documentation of at least 1 set of complete lung function testing. Patients who had received a lung transplant were excluded. The study was approved by the institutional review board of USC Health Sciences Center.

Spirometry, lung volumes by body plethysmography and diffusion capacity were obtained in seated position (MedGraphics, System 1070, St. Paul, MN, USA). Measurements were obtained at least 4 hours after bronchodilator treatment. The cut-off point of $\mathrm{FEV}_{1} / \mathrm{FVC}$ for COPD was 0.7 [21]. Predicted values for post-bronchodilator $\mathrm{FEV}_{1}, \mathrm{FVC}$ and $\mathrm{FEV}_{1} / \mathrm{FVC}$ were from Schoenberg et al. [22], and for subdivisions of lung volume from Crapo et al. [23]. IC, IC/TLC and FRC/TLC were used as measures of lung hyperinflation. Predicted values for IC were obtained from the difference between the predicted values for TLC and FRC [24]. All lung function testing was performed according to ATS/ERS guidelines [25].

Pulmonary exacerbations-defined by necessity for intravenous antibiotics, administered during hospitalization-were documented yearly for three consecutive years. One and 3 year exacerbations represent the number of pulmonary exacerbations within the first 1 and first 3 calendar years, respectively, of the subject's initial 
evaluation. All cause mortality was recorded. The respiratory domain of the standard Cystic Fibrosis Questionnaire-Revised (CFQ-R-Respiratory) [26] was used as a measure of quality of life. The respiratory domain includes 6 questions each worth 4 points. CFQ-R-Respiratory score was recorded as a percentage of the total 24 points possible within the respiratory domain, with a higher number indicating a more favorable score [27]. All patients received bronchodilators, hypertonic saline and mucolytics, and some were prescribed inhaled antibiotics for chronic suppression of pathogens.

\subsection{Statistical Analysis}

Statistical analyses were performed using IBM SPSS Statistics. Bivariate correlations using Pearson's coefficient were used to assess for associations between lung function, number of pulmonary exacerbations and CFQR-Respiratory [28]. One-way analysis of variance (ANOVA) was used to compare exacerbation frequency, lung function, and CFQ-R-Respiratory between individuals who expired during the 15-year study period and individuals who survived. Backwards regression analysis was used to determine the order of magnitude of correlation between exacerbation frequency and lung function variables. A $p \leq 0.05$ was taken as significant.

\section{Results}

The records of 200 patients were reviewed. Of these, 68 patients met inclusion and exclusion criteria. Their anthropometric and physiologic data are shown in Table 1 . The population was predominantly Caucasian (84\%) with a small minority of Hispanics and African Americans. Six participants had a history of pulmonary hypertension. Three had a history of lobectomy, 38 had cystic fibrosis-related diabetes, and one had a history of pneumothorax. Twenty-six individuals were homozygous for F508del, 32 were heterozygous for F508del, 8 individuals had other mutations, and 1 was unknown. Mean baseline CFQ-R-Respiratory score was 75\%. Mean $\mathrm{FEV}_{1} / \mathrm{FVC}$, IC, IC/TLC and FRC/TLC was $64 \%, 90 \%, 43 \%$ and $57 \%$, respectively.

The number of acute exacerbations requiring hospitalization were (mean \pm SD) $2 \pm 0.9,2.5 \pm 1$, and $2 \pm 1$ in years 1, 2, and 3, respectively. As shown in Table 2, FEV, FVC, FEV ${ }_{1} / F V C$, IC, IC/TLC, FRC/TLC and RV/TLC all correlated with number of exacerbations over 1 and 3 years. Both $\mathrm{FEV}_{1}$ and IC were negatively correlated with pulmonary exacerbations over a 3 year period $\left(p=0.004, r^{2}=0.127 ; p<0.001, r^{2}=0.307\right.$, respectively), while FRC/TLC correlated positively with exacerbations $(\mathrm{p}=0.007)$. TLC alone did not correlate with exacerbations, while FRC alone exhibited a weak correlation. As expected, FEV ${ }_{1}$, FVC, IC and their ratios with TLC correlated negatively with exacerbation frequency, while FRC/TLC and RV/TLC exhibited positive relationships. Backwards regression analysis between exacerbations over the first year and lung function showed that the highest correlation was with $\mathrm{FEV}_{1} \%$ predicted $\left(\mathrm{r}^{2}=0.251\right.$, $\mathrm{p}=0.001$ Table $\left.3(\mathrm{a})\right)$. The next closest correlation was with FVC \% predicted $\left(r^{2}=0.271, p=0.002\right)$. Backwards regression analysis over 3 years showed that the highest correlation was with the IC \% predicted $\left(r^{2}=0.311, p<0.001\right.$ Table 3(b)). The next closest correlation was with $\mathrm{FEV}_{1} \%$ predicted $\left(\mathrm{r}^{2}=0.330, \mathrm{p}<0.001\right)$. We found no correlation between lung function and CFQ-R-Respiratory score. The relationship of FEV ${ }_{1}$, FVC, IC, and FRC/TLC to 3-year exacerbations is depicted in Figure 1. The numbers of exacerbations above and below critical cutoff values for normality of the same variables are shown in Figure 2.

Twelve out of the 68 individuals originally included in the analysis expired over the 15-year study period. We examined differences in pulmonary exacerbations, CFQ-R-Respiratory and lung function by mortality status (Figure 3 and Figure 4). Only CFQ-R-Respiratory was lower in individuals who had expired during the study period in comparison to survivors $(\mathrm{p}=0.005)$. Mortality, however, did not correlate with baseline $\mathrm{FEV}_{1}, \mathrm{FVC}$, IC/TLC, FRC/TLC or RV/TLC (Figure 4).

\section{Discussion}

Finding clinically relevant parameters of disease severity provides useful guideposts in the ongoing management of CF. While disease severity can be measured in many ways in CF, we focused on examination of the CFQ-RRespiratory score, pulmonary exacerbations, and mortality because these values provide a patient-centered measurement of health. To our knowledge this is the first study to demonstrate that lung hyperinflation, as measured by IC and FRC/TLC, correlates with frequency of pulmonary exacerbations in adults with cystic fibrosis. We have also confirmed the utility of the CFQ-R-Respiratory score by demonstrating its association with 
Table 1. Anthropometric and physiologic data.

n (\%), mean (SD)

Gender (\% female)

35 (52\%)

Age

29 (8.9)

Body Mass Index $\left(\mathrm{kg} / \mathrm{m}^{2}\right)$

23 (3.7)

\section{Ethnicity}

Caucasian

Hispanic

African-American

Medical History

Pulmonary Hypertension

$6(9 \%)$

Cystic Fibrosis Related Diabetes

38 (56\%)

Pneumothorax

Lobectomy

Genotype

F508del Homozygous

$26(38 \%)$

F508del Heterozygous

33 (49\%)

Other

Mortality (\% expired)

$13(20 \%)$

0.7 (0.9)

2.3 (2.5)

Total exacerbations over 3 years

CFQ-R-Respiratory Score (\%)

\section{Lung Function}

$\mathrm{FEV}_{1}$ (\% pred)

FVC (\% pred)

FEV1/FVC (\%)

TLC (\% pred)

102 (15)

IC (\% pred)

IC/TLC (\%)

FRC (\% pred)

107 (31)

FRC/TLC (\%)

RV (\% pred)

176 (79)
RV/TLC (\%)

$43(16)$

Values above are expressed as n (\%) or mean $( \pm \mathrm{SD})$ as appropriate. Expired subjects defined as subjects that were expired at the end of the 15 year data collection period. Abbreviations: BMI body mass index, $\mathbf{F E V} \mathbf{V}_{\mathbf{1}}$ forced expiratory volume 1 second, FVC forced vital capacity, IC inspiratory capacity, FRC functional residual capacity, RV residual volume, TLC total lung capacity, CFQ-R-Respiratory cystic fibrosis questionnaire revised respiratory domain. 
Table 2. Bivariate correlations comparing lung function to pulmonary exacerbations and CFQ-R.

\begin{tabular}{ccccc}
\hline & & 1 Year Exacerbations & 3 Year Exacerbations & CFQ-R-Respiratory Score \\
\hline FEV $\mathbf{1}$ (\% pred) & Pearson Coef & $-0.326^{* *}$ & $-0.356^{* *}$ & 0.213 \\
& p-value & 0.007 & 0.004 & 0.193 \\
FVC (\% pred) & Pearson Coef & $-0.252^{*}$ & $-0.345^{* *}$ & 0.18 \\
& p-value & 0.041 & 0.006 & 0.273 \\
FEV $/$ /FVC & Pearson Coef & $-0.338^{* *}$ & $-0.295^{*}$ & 0.242 \\
& p-value & 0.005 & 0.018 & 0.132 \\
TLC (\% pred) & Pearson Coef & 0.156 & 0.04 & -0.019 \\
& p-value & 0.223 & 0.76 & 0.912 \\
IC (\% pred) & Pearson Coef & $-0.425^{* *}$ & $-0.554^{* *}$ & 0.172 \\
& p-value & 0.004 & $<0.001$ & 0.315 \\
IC/TLC & Pearson Coef & $-0.389^{* *}$ & $-0.412^{* *}$ & 0.099 \\
& p-value & 0.01 & 0.007 & 0.573 \\
FRC (\% pred) & Pearson Coef & $0.308^{*}$ & 0.197 & -0.069 \\
& p-value & 0.045 & 0.212 & 0.695 \\
FRC/TLC & Pearson Coef & $0.389^{*}$ & $0.412^{* *}$ & -0.098 \\
& p-value & 0.01 & 0.007 & 0.574 \\
& Pearson Coef & $0.361^{* *}$ & $0.323^{*}$ & -0.141 \\
\hline & p-value & 0.003 & 0.011 & 0.392 \\
\hline
\end{tabular}

Abrreviations: 1 and 3 year exacerbations number of pulmonary exacerbations within the first 1 and first 3 years, respectively, of the subject's initial evaluation. $\mathbf{F E V}_{\mathbf{1}}$ forced expiratory volume 1 second, FVC forced vital capacity, IC inspiratory capacity, FRC functional residual capacity, RV residual volume, TLC total lung capacity, CFQ-R-Respiratory cystic fibrosis questionnaire revised respiratory domain. ${ }^{* *}$ Correlation is significant at the 0.01 level (2. tailed). ${ }^{*}$ Correlation is significant at the 0.05 level (2. tailed).

Table 3. (a) Backward regression analysis of lung function vs exacerbations over 1 year. (b) Backward regression analysis of lung function vs exacerbations over 3 years

(a)

\begin{tabular}{lcc}
\hline & $\mathbf{r}^{\mathbf{2}}$ & p value \\
\hline Model 1 $^{\mathbf{a}}$ & 0.322 & 0.074 \\
Model 2 $^{\mathbf{b}}$ & 0.321 & 0.043 \\
Model 3 $^{\mathbf{c}}$ & 0.321 & 0.023 \\
Model 4 $^{\mathbf{d}}$ & 0.310 & 0.014 \\
Model 5 $^{\mathbf{e}}$ & 0.296 & 0.008 \\
Model 6 $^{\mathbf{f}}$ & 0.291 & 0.004 \\
Model 7 $^{\mathbf{g}}$ & 0.271 & 0.002 \\
Model 8 $^{\mathbf{h}}$ & 0.251 & 0.001 \\
\hline
\end{tabular}

Backward regression analysis pulmonary functions as independent variables and exacerbations over 1 year as the dependent variable. Independent variables are removed from each consecutive model as detailed below: a. Predictors: $\mathrm{FEV}_{1} \%$ pred, TLC \% pred, RV/TLC \% pred, IC/TLC, IC \% pred, FVC \% pred, FEV 1 FVC, FRC \% pred; b. Predictors: FEV $_{1} \%$ pred, TLC \% pred, RV/TLC \% pred, IC/TLC, IC \% pred, FVC \% pred, FEV $/$ FVC; c. Predictors: FEV $\%$ pred, TLC \% pred, IC/TLC, IC \% pred, FVC \% pred, $\mathrm{FEV}_{1} / \mathrm{FVC}$; d. Predictors: $\mathrm{FEV}_{1} \%$ pred, TLC \% pred, IC/TLC, IC \% pred, FVC \% pred; e. Predictors: FEV $_{1} \%$ pred, IC/TLC, IC \% pred, FVC \% pred; f. Predictors: FEV $1 \%$ pred, IC \% pred, FVC \% pred; g. Predictors: $\mathrm{FEV}_{1} \%$ pred, FVC \% pred; h. Predictors: $\mathrm{FEV}_{1} \%$ pred. 
(b)

\begin{tabular}{lcc}
\hline & $\mathbf{r}^{2}$ & p value \\
\hline Model 1 $^{\mathbf{a}}$ & 0.454 & 0.006 \\
Model 2 $^{\mathbf{b}}$ & 0.454 & 0.003 \\
Model 3 $^{\mathbf{c}}$ & 0.444 & 0.001 \\
Model 4 $^{\mathbf{d}}$ & 0.423 & 0.001 \\
Model 5 $^{\mathbf{e}}$ & 0.393 & 0.001 \\
Model 6 $^{\mathbf{f}}$ & 0.359 & 0.001 \\
Model 7 $^{\mathbf{g}}$ & 0.330 & $<0.001$ \\
Model 8 $^{\mathbf{h}}$ & 0.311 & $<0.001$ \\
\hline
\end{tabular}

Backward regression analysis pulmonary functions as independent variables and exacerbations over 3 years as the dependent variable. Independent variables are removed from each consecutive model as detailed below: a. Predictors: RV/TLC \% pred, TLC \% pred, $\mathrm{FEV}_{1} / \mathrm{FVC}$, IC/TLC, FVC \% pred, IC \% pred, FRC \% pred, $\mathrm{FEV}_{1} \%$ pred; b. Predictors: RV/TLC \% pred, TLC \% pred, $\mathrm{FEV}_{1} / \mathrm{FVC}$, IC/TLC, FVC \% pred, IC \% pred, FEV $1 \%$ pred; c. Predictors: RV/TLC \% pred, TLC \% pred, FEV $1 /$ FVC, FVC \% pred, IC $\%$ pred, $\mathrm{FEV}_{1} \%$ pred; d. Predictors: RV/TLC \% pred, TLC $\%$ pred, $\mathrm{FEV}_{1} / \mathrm{FVC}$, IC $\%$ pred, $\mathrm{FEV}_{1} \%$ pred; e. Predictors: RV/TLC \% pred, FEV 1 FVC, IC \% pred, $\mathrm{FEV}_{1} \%$ pred; f. Predictors: RV/TLC \% pred, IC \% pred, $\mathrm{FEV}_{1} \%$ pred; g. Predictors: IC \% pred, $\mathrm{FEV}_{1} \%$ pred; h. Predictors: IC \% pred.
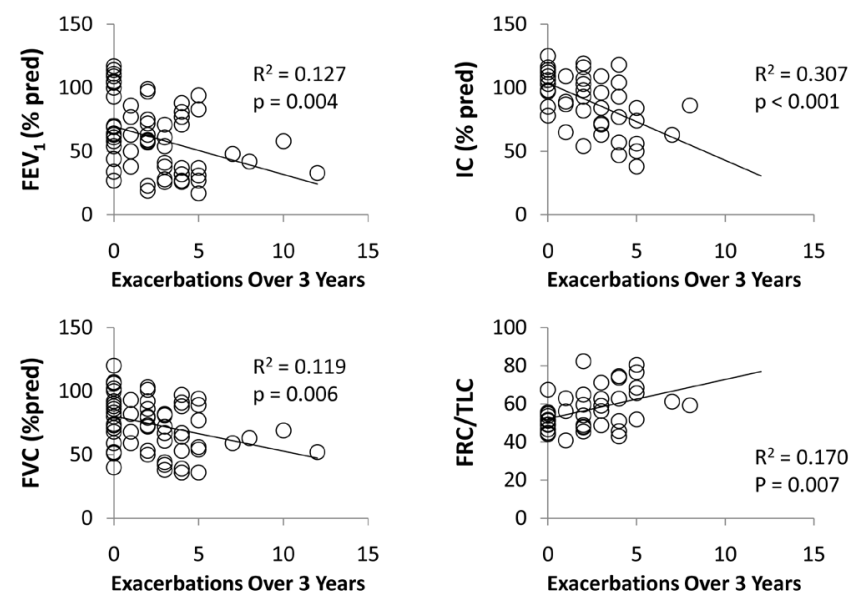

Figure 1. Correlations between lung function and exacerbations over 3 years. Relation of lung functions to total number of exacerbations over three years. Abbreviations: $\mathrm{FEV}_{1}$ forced expiratory volume 1 second, FVC forced vital capacity, TLC total lung capacity, IC inspiratory capacity, FRC functional residual capacity.

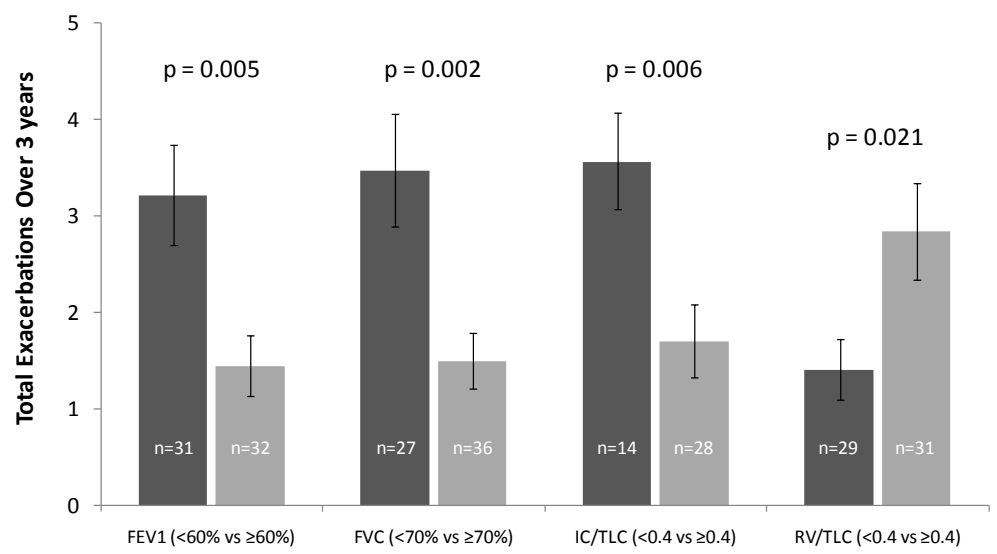

Figure 2. Comparison of mean exacerbations among high vs low lung function. Lung function is shown along the $\mathrm{x}$-axis and is dichotomized into two groups. Cutoff values defining high and low groups are shown along the $\mathrm{x}$-axis. Error bars represent mean \pm SEM. Mean exacerbations over three years is compared between groups. Abbreviations: $\mathrm{FEV}_{1}$ forced expiratory volume 1 second, FVC forced vital capacity, TLC total lung capacity, IC inspiratory capacity, RV residual volume. 


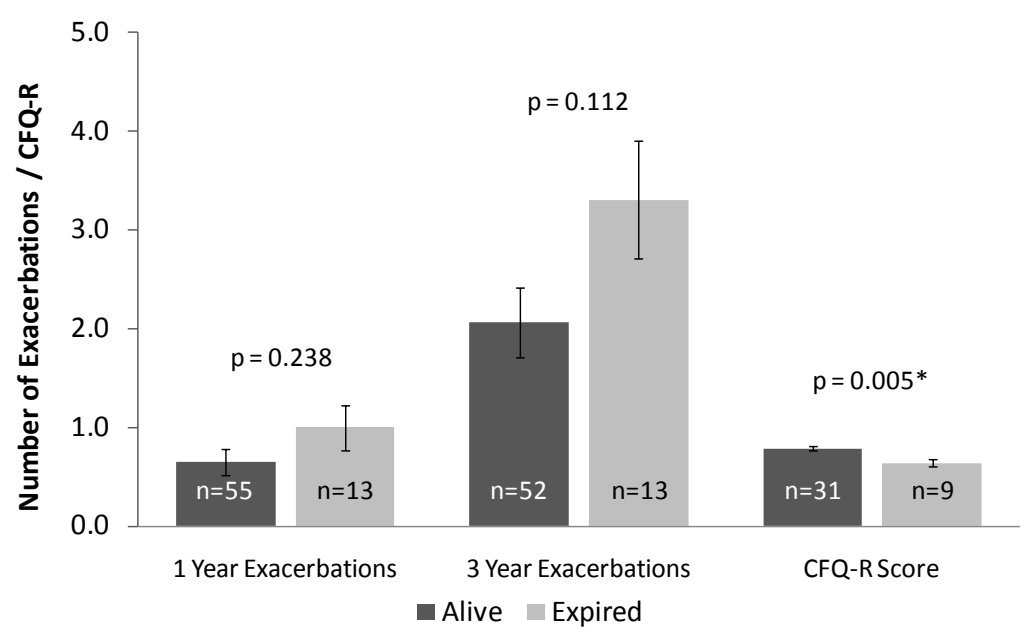

Figure 3. Comparisons of means of pulmonary exacerbations and CFQ-R grouped by mortality status. 1 and 3 year exacerbations denote total number of pulmonary exacerbations within the first 1 and 3 years, respectively, of the subjects' initial evaluation. Alive and expired denote subjects who were living or deceased respectively at the end the 15 year data collection period. CFQ-R-Respiratory cystic fibrosis questionnaire revised respiratory domain. Error bars represent mean \pm SEM.

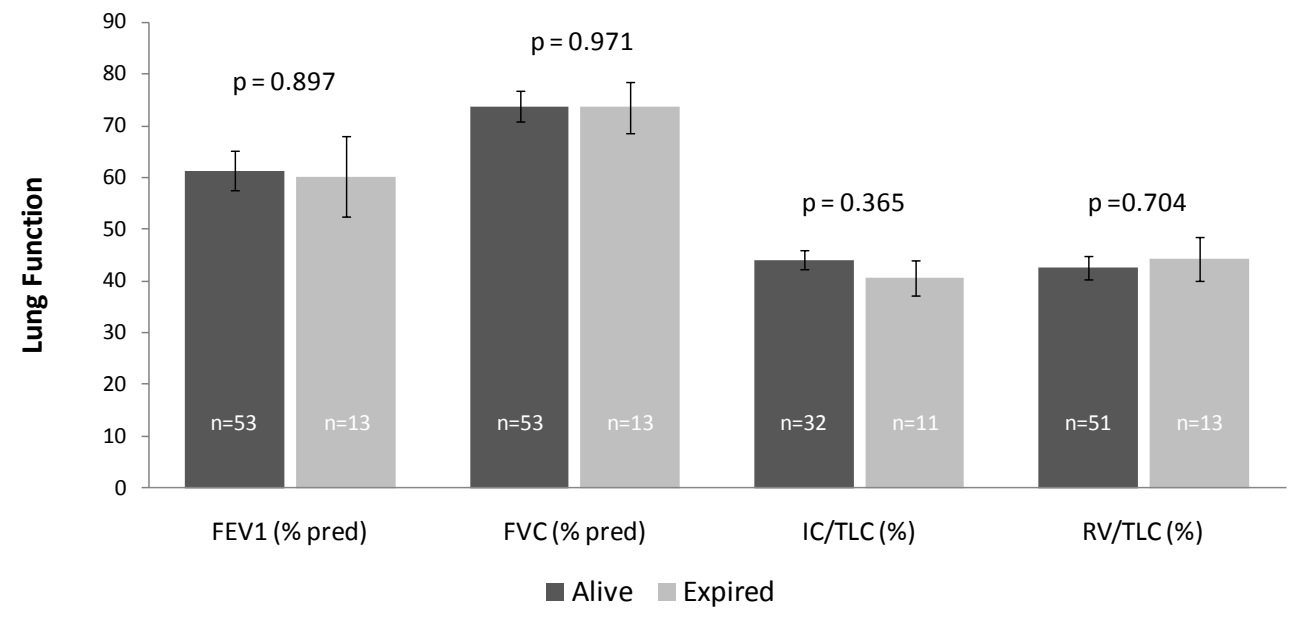

Figure 4. Comparisons of means of lung function grouped by mortality status. Alive and expired denote subjects who were living or deceased respectively at the end the 15 year data collection period. Abbreviations: $\mathrm{FEV}_{1}$ forced expiratory volume 1 second, FVC forced vital capacity, TLC total lung capacity, IC inspiratory capacity, RV residual volume. Error bars represent mean \pm SEM.

mortality. Our findings suggest that lung hyperinflation is as important as $\mathrm{FEV}_{1}$ in relation to frequency of pulmonary exacerbations.

It might be expected that patients with the most severe airflow limitation would be the most dyspneic. Yet, some patients with severe airway obstruction, as reflected by the $\mathrm{FEV}_{1}$, have few symptoms, while others with minimal flow limitation exhibit severe dyspnea. In patients with COPD, smoking and advanced age contribute to peripheral airway closure as a result of which, closing volume exceeds FRC [29] [30]. Sequential opening and closing of the airways produces epithelial injury in respiratory and membranous bronchioles. Similar changes likely result from chronic inflammation with intercurrent infectious exacerbations in patients with CF, resulting in peripheral airway closure and increase in closing volume, and eventually hyperinflation. Use of the negative expiratory pressure technique during quiet tidal breathing has demonstrated that tEFL at rest is associated with lower IC [11]. Since maximal tidal volume correlates with IC during exercise, patients with tEFL at rest exhibit an increase in end-expiratory lung volume and a further decrease in IC with concomitant exercise limitation. By contrast, in non-tEFL patients IC is usually normal, and $\mathrm{FEV}_{1} / \mathrm{FVC}$ is the sole predictor of exercise limitation 
[10]. This is mainly due to the fact that a low $\mathrm{FEV}_{1} / \mathrm{FVC}$ ratio is associated with a maximal expiratory flowvolume curve with an upward concavity with little expiratory flow over the resting tidal volume range. Using the NEP technique, Goetghebeur et al. [31] found that in CF patients severe chronic dyspnea and tidal flow limitation during resting breathing in seated position are uncommon and seen only when the $\mathrm{FEV}_{1}$ is $<50 \%$ predicted (14\% prevalence in their CF patients, with FEV1 < 30\% predicted). The prevalence of tEFL was lower than in a study of COPD patients [8], attributed to lower lung elastic recoil and more peripheral lung disease in the COPD patients, and possibly due to persistent inspiratory muscle contraction resulting increased EELV thus avoiding tEFL. Thus patients without tEFL at rest but with a low $\mathrm{FEV}_{1} / \mathrm{FVC}$ are more likely to exhibit tEFL during exercise than patients who have a normal $\mathrm{FEV}_{1} / \mathrm{FVC}$.

That lung hyperinflation would correlate significantly with pulmonary exacerbations but not with CFQ-RRespiratory or mortality is not surprising. Recent studies suggest that disease severity in CF is impacted by a large number of factors, reflective of the multi-system nature of the disease. Lung function as measured by FEV ${ }_{1}$ correlates with most domains of the CFQ-R but not all, and furthermore depressive symptoms correlate strongly with total CFQ-R scores even when controlling for $\mathrm{FEV}_{1}$ [6]. Britto et al. [5] similarly reported a correlation between number of exacerbations and some domains of questionnaire based measures of quality of life but not others. Burker et al. [7] demonstrated the importance of employment status and education level on quality of life. Lung hyperinflation, exacerbations, questionnaire-based quality of life, and mortality are interrelated in complex ways in CF as they are in COPD [32]-[34].

There were limitations to our study. Unfortunately, not enough patients $(n=12)$ completed a 6MWD to allow analysis of this variable in relation to lung hyperinflation. Analysis of the full CFQ-R was not included in this study because only data on the respiratory domain was available retrospectively. In addition, we would have preferred to express the numbers of exacerbations and their relation to lung function variables on a per-year basis; however, as is often a challenge with retrospective studies, this was not possible as lung function testing subsequent to the baseline measurements was performed at random, irregular intervals, making it difficult to match up the exacerbations and lung functions within discreet time segments. We therefore elected to examine the total number of exacerbations within 1- and 3-year time frames with respect to baseline functional variables only. Moreover, the lack of difference amongst baseline lung function variables between living and expired patients does not exclude the effects of lead time: that is, the possibility that some patients may have experienced a rapid decline in lung function within the 15-year period that, had sequential testing been performed, might have predicted which patients were likely to develop respiratory failure and to have died from their illness. Lastly, this study was underpowered to detect associations between lung hyperinflation and mortality. A number of future inquiries are possible at this time. Namely, a large-scale prospective trial examining the relationship between lung function and disease severity and outcome in adult CF patients is missing from current literature.

\section{Conclusion}

$\mathrm{FEV}_{1}$ and lung hyperinflation —as measured by IC and FRC/TLC—are both associated with pulmonary exacerbation frequency. This suggests that chronic hyperinflation contributes significantly to disease severity in adult cystic fibrosis.

\section{References}

[1] Kraemer, R., Blum, A., Schibler, A., Ammann, R.A. and Gallati, S. (2005) Ventilation in Homogeneities in Relation to Standard Lung Function in Patients with Cystic Fibrosis. American Journal of Respiratory and Critical Care Medicine, 171, 371-378. http://dx.doi.org/10.1164/rccm.200407-948OC

[2] Kraemer, R., Baldwin, D.N., Ammann, R.A., Frey, U. and Gallati, S. (2006) Progression of Pulmonary Hyperinflation and Trapped Gas Asociated with Genetic and Environmental Factors in Children with Cystic Fibrosis. Respiratory Research, 7, 138-153. http://dx.doi.org/10.1186/1465-9921-7-138

[3] Aurora, P., Bush, A., Gustaffson, P., Oliver, C., Wallis, C., Price, J., Stroobant, J., Carr, S. and Stocks, J. (2005) Multiple-Breath Washout as a Marker of Lung Disease in Preschool Children with Cystic Fibrosis. American Journal of Respiratory and Critical Care Medicine, 171, 249-256. http://dx.doi.org/10.1164/rccm.200407-895OC

[4] Bellemare, F. and Grassino, A. (1982) Effect of Pressure and Timing of Contraction on Diaphragm Fatigue. Journal of Applied Physiology, 53, 1190-1195.

[5] Britto, M.T. (2002) Impact of Recent Pulmonary Exacerbations on Quality of Life in Patients with Cystic Fibrosis. 
Chest, 121, 64-72. http://dx.doi.org/10.1378/chest.121.1.64

[6] Riekert, K.A. (2007) The Association between Depression, Lung Function, and Health-Related Quality of Life among Adults with Cystic Fibrosis. Chest, 132, 231-237. http://dx.doi.org/10.1378/chest.06-2474

[7] Burker, E.J. (2004) Psychological and Educational Factors: Better Predictors of Work Status than FEV 1 in Adults with Cystic Fibrosis. Pediatric Pulmonology, 38, 413-418. http://dx.doi.org/10.1002/ppul.20090

[8] Eltayara, L., Becklake, M.R., Volta, C.A. and Milic-Emili, J. (1996) Relationship between Chronic Dyspnea and Expiratory Flow Limitation in Patients with Chronic Obstructive Pulmonary Disease. American Journal of Respiratory and Critical Care Medicine, 154, 1726-1734. http://dx.doi.org/10.1164/ajrccm.154.6.8970362

[9] Tantucci, C., Duguet, A., Similowski, T., Zelter, M., Derenne, J.-P. and Milic-Emili, J. (1998) Effect of Salbutamol on Dynamic Hyperinflation in Chronic Obstructive Pulmonary Disease Patients. European Respiratory Journal, 12, 799804. http://dx.doi.org/10.1183/09031936.98.12040799

[10] Diaz, O., Villafranca, C., Ghezzo, H., Borzone, G., Leiva, A., Milic-Emili, J., et al. (2000) Role of Inspiratory Capacity on Exercise Tolerance in COPD Patients with and Without Tidal Expiratory Flow Limitation at Rest. European Respiratory Journal, 16, 269-275. http://dx.doi.org/10.1034/j.1399-3003.2000.16b14.X

[11] Koulouris, N.G., Dimopoulou, I., Valta, P., Finkelstein, R., Cosio, M.G. and Milic-Emili, J. (1997) Detection of Expiratory Flow Limitation during Exercise in COPD Patients. Journal of Applied Physiology, 82, 723-731.

[12] O’Donnell, D.E., Revill, S.M. and Webb, K.A. (2001) Dynamic Hyperinflation and Exercise Intolerance in Chronic Obstructive Pulmonary Disease. American Journal of Respiratory and Critical Care Medicine, 164, 770-777. http://dx.doi.org/10.1164/ajrccm.164.5.2012122

[13] Milic-Emili, J., Koulouris, N. and Tantucci, C. (2005) Spirometric Predictions of Exercise Limitation in Patients with Chronic Obstructive Pulmonary Disease. In: Hamid, Q., Shannon, J. and Martin, J., Eds., Physiologic Basis of Disease, Chap. 58, BC Dekker Inc., Hamilton, 671-679.

[14] Casanova, C., Cote, C., de Torres, J.P., et al. (2005) Inspiratory-to-Total Lung Capacity Ratio Predicts Mortality in Patients with Chronic Obstructive Pulmonary Disease. American Journal of Respiratory and Critical Care Medicine, 171, 591-597. http://dx.doi.org/10.1164/rccm.200407-867OC

[15] Moore, A., Soler, R.S., Cetti, E.J., et al. (2010) Sniff Nasal Inspiratory Pressure versus IC/TLC Ratio as Predictors of Mortality in COPD. Respiratory Medicine, 104, 1319-1325. http://dx.doi.org/10.1016/j.rmed.2010.03.001

[16] French, A., Balfe, D., Mirocha, J.M., et al. (2015) The Inspiratory/Total Lung Capacity Ratio as a Predictor of Survival in an Emphysematous Phenotype of Chronic Obstructive Pulmonary Disease. International Journal of Chronic Obstructive Pulmonary Disease, 10, 1305-1312.

[17] Stern, R.C. (1997) The Diagnosis of Cystic Fibrosis. The New England Journal of Medicine, 336, 487-491. http://dx.doi.org/10.1056/NEJM199702133360707

[18] Rosenstein, B.J. and Cutting, G.R., for the Cystic Fibrosis Foundation Consensus Panel (1998) The Diagnosis of Cystic Fibrosis: A Consensus Statement. The Journal of Pediatrics, 132, 589-595. http://dx.doi.org/10.1016/S0022-3476(98)70344-0

[19] Liechti-Gallati, S., Schneider, V., Neeser, D. and Kraemer, R. (1999) Two Buffer PAGE System-Based SSCP/HD Analysis: A General Protocol for Rapid and Sensitive Mutation Screening in Cystic Fibrosis and Any Other Human Genetic Disease. European Journal of Human Genetics, 7, 590-598. http://dx.doi.org/10.1038/sj.ejhg.5200338

[20] Bennett, L.C. and Kraemer, R. (2000) Buccal Cell DNA Analysis in Premature and Term Neonates: Screening for Mutations of the Complete Coding Region for the Cystic Fibrosis Transmembrane Conductance Regulator. European Journal of Pediatrics, 159, 99-102. http://dx.doi.org/10.1007/PL00013814

[21] Vestbo, J., Hurd, S.S., Agustí, A.G., Jones, P.W., Vogelmeier, C., Anzueto, A., Barnes, P.J., Fabbri, L.M., Martinez, F.J., Nishimura, M., Stockley, R.A., Sin, D.D. and Rodriguez-Roisin, R. (2013) Global Strategy for the Diagnosis, Management, and Prevention of Chronic Obstructive Pulmonary Disease: GOLD Executive Summary. American Journal of Respiratory and Critical Care Medicine, 187, 347-365. http://dx.doi.org/10.1164/rccm.201204-0596PP

[22] Schoenberg, J.B., Beck, G.J. and Bouhuys, A. (1978) Growth and Decay of Pulmonary Function in Healthy Blacks and Whites. Respiration Physiology, 33, 367-393. http://dx.doi.org/10.1016/0034-5687(78)90063-4

[23] Crapo, R.O., Morris, A.H., Clayton, P.D. and Nixon, C.R. (1982) Lung Volumes in Healthy Nonsmoking Adults. Bulletin Européen de Physiopathologie Respiratoire, 18, 419-425.

[24] Bates, D.V. (1989) Respiratory Function in Disease. Saunders, Philadelphia, 108-109.

[25] Pellegrino, R., Viegi, G., Brusasco, V., et al. (2005) Interpretative Strategies for Lung Function Tests. European Respiratory Journal, 26, 948-968. http://dx.doi.org/10.1183/09031936.05.00035205

[26] Quittner, A.L., Buu, A., Messer, M., Modi, A. and Watrous, M. (2005) Development and Validation of the Cystic Fibrosis Questionnaire in the United States. A Health-Related Quality-of-Life Measure for Cystic Fibrosis. Chest, 128, 
2347-2354. http://dx.doi.org/10.1378/chest.128.4.2347

[27] Quittner, A.L., Modi, A.C., Wainwright, C., Otto, K., Kirihara, J. and Montgomery, A.B. (2009) Determination of the Minimal Clinically Important Difference Scores for the Cystic Fibrosis Questionnaire-Revised Respiratory Symptom Scale in Two Populations of Patients with Cystic Fibrosis and Chronic Pseudomonas Aeruginosa Airway Infection. Chest, 135, 1610-1618. http://dx.doi.org/10.1378/chest.08-1190

[28] Dixon, W.J. and Massey Jr., F.J. (1983) Introduction to Statistical Analysis. 4th Edition, McGraw-Hill, New York, 385-414.

[29] McCarthy, D.S., Spencer, R., Greene, R. and Milic-Emili, J. (1972) Measurement of “Closing Volume” as a Simple and Sensitive Test for Early Detection of Small Airway Disease. The American Journal of Medicine, 52, 747-753. http://dx.doi.org/10.1016/0002-9343(72)90080-0

[30] Milic-Emili, J. (2004) Does Mechanical Injury of the Peripheral Airways Play a Role in the Genesis of COPD in Smokers? Journal of Chronic Obstructive Pulmonary Disease, 1, 85-92. http://dx.doi.org/10.1081/COPD-120028700

[31] Goetghebeur, D., Sarni, D., Grossi, Y., Leroyer, C., Ghezzo, H., Milic-Emili, J. and Bellet, M. (2002) Tidal Expiratory Flow Limitation and Chronic Dyspnea in Patients with Cystic Fibrosis. European Respiratory Journal, 19, 492-498. http://dx.doi.org/10.1183/09031936.02.00220702

[32] Schols, A.M.W.J., Slangen, J., Volovics, L. and Wouters, E.F.M. (1998) Weight Loss Is a Reversible Factor in the Prognosis of Chronic Obstructive Pulmonary Disease. American Journal of Respiratory and Critical Care Medicine, 157, 1791-1797. http://dx.doi.org/10.1164/ajrccm.157.6.9705017

[33] Landbo, C., Prescott, E., Lange, P., Vestbo, J. and Almdal, T.P. (1999) Prognostic Value of Nutritional Status in Chronic Obstructive Pulmonary Disease. American Journal of Respiratory and Critical Care Medicine, 160, 18561861. http://dx.doi.org/10.1164/ajrccm.160.6.9902115

[34] Nishimura, K., Izumi, T., Tsukino, M. and Oga, T. (2002) Dyspnea Is a Better Predictor of 5-Year Survival than Airway Obstruction in Patients with COPD. Chest, 121, 1434-1440. http://dx.doi.org/10.1378/chest.121.5.1434 